\title{
Formation and composition of adsorbates on hydrophobic carbon surfaces from aqueous laccase-maltodextrin mixture suspension
}

\author{
Yendry Regina Corrales Ureña ${ }^{a, b}, *$, Paulo Noronha Lisboa-Filho ${ }^{a}$, Michael Szardenings ${ }^{c}$, \\ Linda Gätjen ${ }^{\mathrm{b}}$, Paul-Ludwig Michael Noeske ${ }^{\mathrm{b}}$, Klaus Rischka ${ }^{\mathrm{b}}$ \\ a UNESP São Paulo State University, Av. Eng. Luiz Edmundo Carrijo Coube, 14-01, Bauru, São Paulo, Brazil \\ ${ }^{\mathrm{b}}$ Fraunhofer Institute for Manufacturing Technology and Advanced Materials IFAM, Wiener Strasse 12, 28359 Bremen, Germany

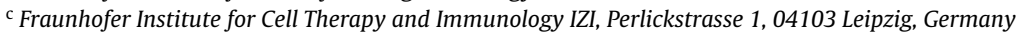

\section{A R T I C L E I N F O}

\section{Article history:}

Received 10 March 2016

Received in revised form 18 May 2016

Accepted 18 May 2016

Available online 24 May 2016

\section{Keywords:}

Laccase

Maltodextrin

Hydrophobic

Bio-functionalization

Carbon

\begin{abstract}
A B S T R A C T
A robust procedure for the surface bio-functionalization of carbon surfaces was developed. It consists on the modification of carbon materials in contact with an aqueous suspension of the enzyme laccase from Trametes versicolor and the lyophilization agent maltodextrin, with the $\mathrm{pH}$ value adjusted close to the isoelectric point of the enzyme. We report in-situ investigations applying Quartz Crystal Microbalance with Dissipation (QCM-D) for carbon-coated sensor surfaces and, moreover, ex-situ measurements with static contact angle measurements, X-ray Photoelectron Spectroscopy (XPS) and Scanning Force Microscopy (SFM) for smooth Highly Oriented Pyrolytic Graphite (HOPG) substrates, for contact times between the enzyme formulation and the carbon material surface ranging from $20 \mathrm{~s}$ to $24 \mathrm{~h}$. QCM-D studies reveals the formation of rigid layer of biomaterial, a few nanometers thin, which shows a strongly improved wettability of the substrate surface upon contact angle measurements. Following spectroscopic characterization, these layers are composed of mixtures of laccase and maltodextrin. The formation of these adsorbates is attributed to attractive interactions between laccase, the maltodextrin-based lyophilization agent and the hydrophobic carbon surfaces; a short-term contact between the aqueous laccase mixture suspension and HOPG surfaces is shown to merely result in de-wetting patterns influencing the results of contact angle measurements. The new enzyme-based surface modification of carbon-based materials is suggested to be applicable for the improvement of not only the wettability of low energy substrate surfaces with fluid formulations like coatings or adhesives, but also their adhesion in contact with hardened polymers.
\end{abstract}

(c) 2016 Elsevier B.V. All rights reserved.

\section{Introduction}

The interaction of proteins with solid surfaces drives their adsorption from liquid formulations and governs the thickness and structure of the adsorbates formed [1]. Tailoring protein adsorption processes towards either avoiding [2] or promoting [3] the attachment of adsorbate structures is especially challenging when using formulations of biopolymers. When aiming for proteinresistant monolayers, characteristics as hydrophilicity, hydrogen bond acceptors groups, polymer net charge and hydrogen bond donor groups may be addressed [1]; criteria for optimization

\footnotetext{
* Corresponding author at: National Nanotechnology Laboratory LANOTEC, Pavas, $1.3 \mathrm{~km}$ north from the USA embassy, San José, Costa Rica.

E-mail addresses: yendry386@hotmail.com, yendry.corrales.urena@gmail.com (Y.R. Corrales Ureña).
}

are summarized; within the so-called Whiteside rules. However, when aiming for strongly adhering biopolymer layers, individual approaches are required which may predominantly rely on covalent, polar or dispersive interactions. The adsorption process and the resulting adsorbates depend on the system combination given by the solid surface, the liquid solvent and the protein [4].

Carbon materials often provide hydrophobic low-energy surfaces [5] which can be used as potential substrates for enzyme adsorption in applications such as biosensors [6]. The interaction of laccases with carbon-based materials has primarily been studied for enzyme immobilization [7] on carbon electrodes for electrochemical applications [8], surface modification of lignocellulosic materials and fibers [9] and the modification of synthetic polymers such as poly(ethersulfone) [10] and polyethylene terephthalate [11] by the grafting of phenolic compounds [12]. The surface properties of carbon materials govern their wetting [13], adsorptive [14], adhesive [15], catalytical [16], electrochemical [17,21], sensorial 
[18], biocompatibility [19], or antimicrobial [20] behavior in a wide range of applications. Tailoring the carbon surface termination and carbon-based interfaces for distinct technological applications may be achieved by surface functionalization profiting from chemical reactions, e.g. introducing chemisorbed oxygen-based species with various resulting functional groups [21] or by profiting from reactions with free organic radicals [22]. Alternatively, layer systems or reactive coatings may be deposited on carbon surfaces, e.g. epoxy systems in sizings for carbon fibers [23], whereby the adhesive properties of these coatings are affected by the carbon surface termination.

Laccases (benzenediol:oxygen oxidoreductase, EC 1.10.3.2) are glycoproteins and multi-copper-containing type enzymes [24]. They contain between 500 and 600 amino acids that are arranged in three $\beta$-barrel domains [25]. Laccases often occur as isoenzymes that oligomerize to form multimeric complexes [24]. They are widely distributed in nature and perform multiple functions linked to either synthesis or degradation processes [26].

Regarding their application in technical processes, laccases are mostly used in the food, textile and paper industries, in oxidation and polymerization processes of undesirable phenolic compounds that affect the organoleptic properties of beverages, as well as for fiber whitening and waste water treatment [27].

When composing liquid protein formulations, polysaccharides are often added, mostly to inhibit dehydration-induced protein unfolding due to the hydrogen bonding between sugar and protein [28]. For example, maltodextrins, i.e. water soluble mixtures of carbohydrates obtained by partial hydrolysis of starches, often are applied for the lyophilization of proteins for the protection from inactivation during freeze-drying [29]. Therefore, proteinpolysaccharide conjugates are used as emulsifying agents for oil-water emulsions in the food industry [30] and for water based adhesives [31].

In the present contribution, the mixture suspension investigated for the modification of carbon based materials is composed of laccase from Trametes versicolor and maltodextrin. We report on a simple method approach based on laccase enzyme-maltodextrin biopolymer formulation for increasing the wettability of low energy substrates without applying organic solvents or energy consuming processes.

\section{Experimental}

\subsection{Materials}

HOPG (quality ZYH from NT-MDT, Russia) cleaved in air was used as a substrate. Acetic acid, sodium acetate and sodium chloride were used in reagent grade (from Aldrich). The laccase mixture suspension (concentration $0.1 \mathrm{mg} / \mathrm{ml}$ ) was prepared with laccase from Trametes versicolor (from ASA Spezialenzyme GmbH, Wolfenbüttel, Germany) in $0.2 \mathrm{M}$ acetate buffer, $\mathrm{pH}$ value 4.75 , containing maltodextrin as a stabilizing agent. This $\mathrm{pH}$ value and the sodium acetate buffer were chosen to study the common conditions in which the enzyme presents the highest catalytic activity [32]. The suspension was prepared at $25^{\circ} \mathrm{C}$ using deionized water and aseptic conditions. Sodium acetate buffer and deionized water were used for rinsing.

\subsection{Preparation of laccase/carbon samples}

For the ex-situ investigations, $100 \mu \mathrm{L} / \mathrm{cm}^{2}$ of the laccase mixture suspension were pipetted onto the HOPG substrate. After the respective contact time, the surface was rinsed gently for some seconds with deionized water, and then blown with air. Finally, the samples were allowed to dry and stored under environmental con- ditions at room temperature and 50\% relative humidity. The buffers and laccase mixture suspensions were freshly prepared prior to each use. Investigations into the effects of short-term contact for $20 \mathrm{~s}, 20 \mathrm{~min}, 30 \mathrm{~min}$ and $24 \mathrm{~h}$ between the laccase mixture suspension and the HOPG were performed using the same concentration and buffer. Results of investigations highlighting the reproducibility of the developed bio-functionalization process are detailed in the following section. In contrast to using HOPG substrates, when investigating the adsorption of laccase on carbon substrates insitu, polystyrene-covered quartz crystals (QSX 310 from Q-Sense, Sweden) were coated with evaporated carbon using a High Vacuum Cressing Carbon coater 208 MTM-10, and the formation of a carbon layer was verified using XPS surface investigations of a silicon substrate positioned next to this sensor sample.

\section{3. $Q C M-D$}

Quartz crystal micro balance with dissipation monitoring (QCMD E4, Q-Sense, Sweden) was used to evaluate the adsorption from aqueous laccase mixture suspension on carbon-coated QCM-D sensors. The adsorption was monitored in real time at $25^{\circ} \mathrm{C}$ and a flow rate of $100 \mu \mathrm{L} / \mathrm{min}$. The sensors were mounted in the flow modules and the system was equilibrated with buffer for $10 \mathrm{~min}$ to generate a stable baseline. The aqueous laccase mixture suspension was then flushed over the carbon surfaces of the crystals. The changes in $\mathrm{f}$ are attributed to the mass adsorbed (including coupled water) and changes in D are attributed to changes on the frictional (viscous) properties of the adsorbed laccase layer. The values were recorded using QSoftTM control software (Q-Sense, Sweden). The adsorbed mass was calculated using the Sauerbrey equation, which details how much the frequency of the oscillator is reduced by the attaching mass. Details of the procedure have been described by Corrales et al. [33], and an assessment of the viscoelastic, mechanical, and dielectric properties of a loaded quartz crystal microbalance has been detailed by Johannsmann [34]. The measurement was repeated two times.

\subsection{X-ray photoelectron spectroscopy}

XPS spectra were taken using a Kratos Ultra facility. The following acquisition parameters were applied: base pressure: $4 \times 10^{-8} \mathrm{~Pa}$, sample neutralization applying low energy electrons $(<5 \mathrm{eV})$, hybrid mode (electrostatic and magnetic lenses are used), take-off angle of electrons $0^{\circ}$, pass energy $20 \mathrm{eV}$ (or $40 \mathrm{eV}$ in the case of most N1s spectra) in high resolution spectra and $160 \mathrm{eV}$ in survey spectra, excitation of photoelectrons by monochromatic $\mathrm{Al}$ $K \alpha$ radiation. The analysis area was elliptically shaped with main axes of $300 \mu \mathrm{m} \times 700 \mu \mathrm{m}$. The information depth thus obtained was approximately $10 \mathrm{~nm}$.

\subsection{Contact angle measurements}

The apparent contact angles were measured with a goniometer (OCA15 Plus, from Data Physics Instruments, Germany) using the sessile drop technique, and HPLC grade water (from Across Organics) was used as probe liquid. The volume of the drops was $10 \mu \mathrm{L}$ for each measurement. The reported contact angle values were an average value from the investigations of at least three separate drops on different substrate areas. The recorded images were analyzed using SCAN 20 Data Physics software.

\subsection{Atomic force microscopy AFM}

The sample topography and local material properties were investigated using a scanning force microscope (SFM) (Digital 

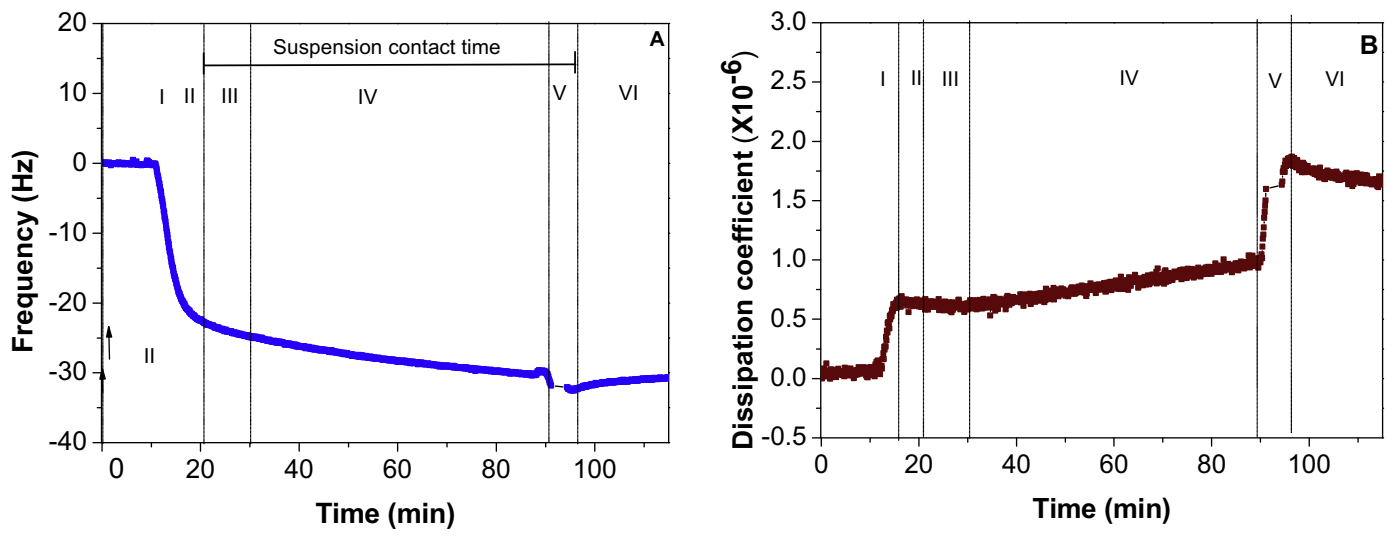

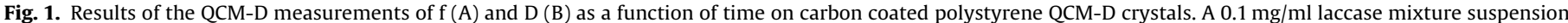
was flushed over the crystal surface (stage II-IV) followed by rinsing with $0.2 \mathrm{M}$ sodium acetate buffer (stage I and V-VI).

Instruments Nanoscope III multimode SPM) operated in the tapping mode in air, using the scanner with ser. no. 6965JVH and Nanoscope software (Version 5.31R1) for acquiring the height and phase images. Cantilevers (model Veeco OTESPA made from $1 \Omega$ silicon; back side of the cantilever covered with $50 \mathrm{~nm} \mathrm{Al} \mathrm{coating)}$ with resonance frequencies of $12-103 \mathrm{kHz}$ were used. For characterizing the structures of the adsorbates, height differences, among other criteria, were evaluated. The values reported are an average of at least 50 height differences measured.

\section{Results and discussion}

This section details first the in-situ QCM-D investigations following the mass gain of carbon-coated substrates immersed in aqueous laccase mixture suspensions. Subsequently, ex-situ investigations focusing on composition and structure of adsorbates formed on HOPG surfaces after contact with such formulations are reported.

\subsection{In-situ investigations}

\subsection{1. $O C M-D$}

The QCM-D technique was applied to characterize the adsorption process from aqueous laccase mixture suspensions on carbon-coated quartz sensors in-situ. During the first eleven minutes of the experiment, and before assessing the adsorption processes, a pure acetate buffer solution was flushed over the crystal surface, thus accounting for the measured signal baselines of frequency f and dissipation coefficient $\mathrm{D}$ being set to zero. As shown in Fig. 1A, the measured frequency of the oscillator remained unchanged during this period of time, stage I. Next, the introduction of the suspension into the QCM-D cell began, and the suspension came into contact with the crystal surface. In the following fifteen minutes a decrease in frequency and an increase in dissipation coefficient were observed. The gradient of the frequency shift was highest shortly after introducing the suspension. The decrease in frequency indicated a mass adsorption, and the decreasing gradient is related to a reduction of the adsorption rate. The findings revealed that the main adsorption event occurred during the first few minutes. A frequency shift of $-25 \mathrm{~Hz}$, as compared to the probe oscillating in the buffer solution, was observed and shown to be the result at the end of stage III. Fig. 1B shows the fast increase in $\mathrm{D}$ to $0.7 \times 10^{-6}$ during stage II following the change of the dissipation coefficient. During stage III, D remained essentially unchanged. Subsequently, within stage IV, the oscillation frequency f decreased slightly, accompanied by an increase in D over approximately $38 \mathrm{~min}$. During this period, saturation was being reached, which could be related to establishing equilibrium between the

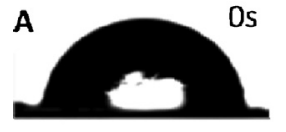

$79 \pm 2^{\circ}$

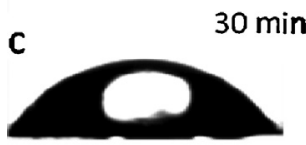

$57 \pm 3^{\circ}$

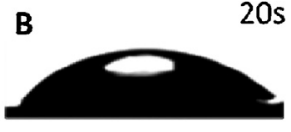

$46 \pm 4^{\circ}$

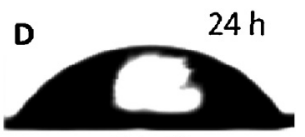

$54 \pm 2^{\circ}$
Fig. 2. Static water contact angle for: A) freshly cleaved HOPG, B) HOPG modified for $20 \mathrm{~s}$, C) $30 \mathrm{~min}$, and D) $24 \mathrm{~h}$. A $0.1 \mathrm{~g} / \mathrm{mL}$ laccase mixture suspension was applied, and then the subtrates were rinsed with deionized water (three replicates).

adsorption and desorption processes. Until the end of stage IV, the total frequency shift was $-30 \mathrm{~Hz}$, and the changes to the dissipation coefficient were not higher than $1 \times 10^{-6}$, which indicated the formation of rigidly attached material [35]. Within stage $\mathrm{V}$ and $\mathrm{VI}$ (rinsing step), the frequency increased slightly, accompanied by an increase in dissipation. These findings could be related to the absorption of water that made the layers more dissipative [36]. As the medium-term contact for $30 \mathrm{~min}$ with flowing buffer solution during stage VI did not affect the adsorbate mass, it was concluded that the adsorbate formed from the formulation of biopolymers was remarkably stable with respect to possible desorption in an aqueous environment. Subsequently, as implied by the experimental findings shown in Fig. 1A, the achieved layer thickness and structure will be estimated and discussed.

Starting from the measured frequency shift, the amount of adsorbed material was calculated using the Sauerbrey equation, and the resulting quasi-gravimetric time dependent mass change is displayed in Fig. 3A. After 79 min of adsorption time, at the end of stage VI, a mass uptake of $530 \mathrm{ng} / \mathrm{cm}^{2}$ was calculated.

Values between 250 and $500 \mathrm{ng} / \mathrm{cm}^{2}$ may be expected as a rule of thumb in a typical protein monolayer [37], with the exact coverage depending on the size and type of the respective protein molecules. Fogel et al. found a value of $569 \mathrm{ng} / \mathrm{cm}^{2}$ for laccase adsorbed on gold by QCM-D, and the authors interpreted that such coverage corresponds to a monolayer [38]. For comparison,supposing a smooth layer of a hydrated polypeptide an effective thickness of $4.1 \mathrm{~nm}$ was calculated, thus yielding a coverage of $530 \mathrm{ng} / \mathrm{cm}^{2}$ based on a density of $1.3 \mathrm{~g} / \mathrm{cm}^{3}$ [36]. It is considered that the adsorption from a suspension containing a mixture of laccase and maltodextrin may have led to a mixed layer composition. In order to identify the actual layer structure, additional ex-situ characterizations will be subsequently presented to verify whether one of these simplified models applies. 

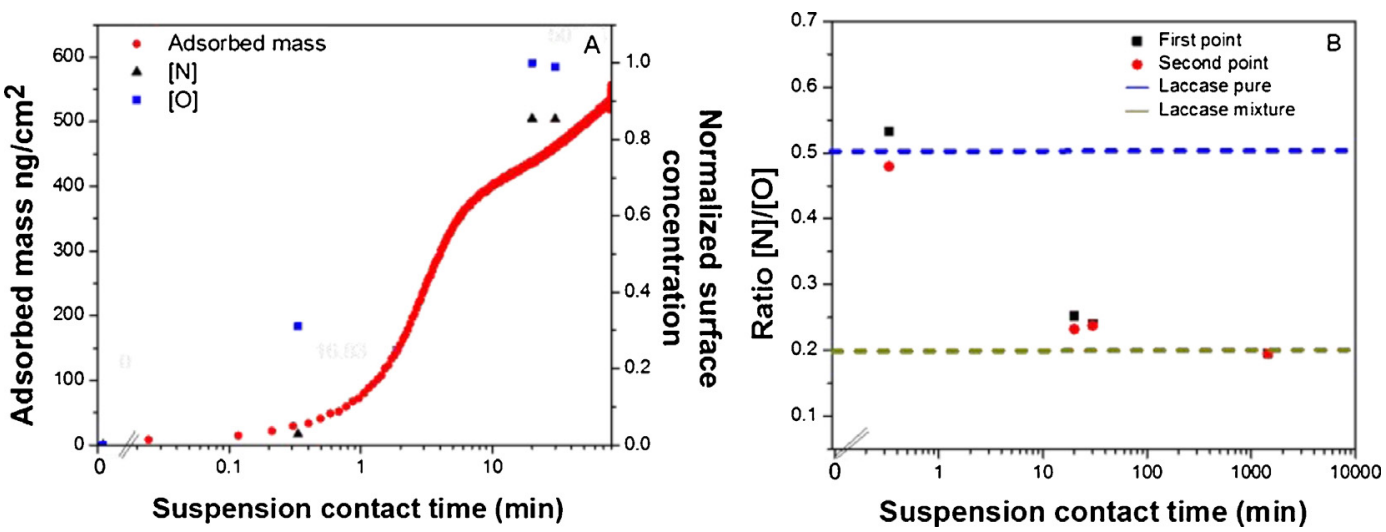

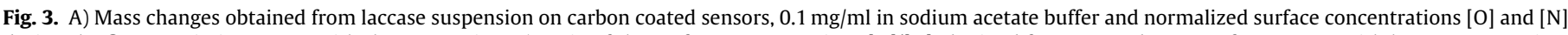

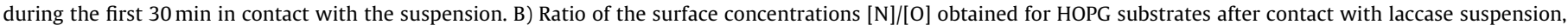
followed by rinsing with deionized water.

\subsection{Ex-situ investigations}

Ex-situ investigations were based on freshly cleaved HOPG substrates in contact with the laccase mixture suspension. As the findings of QCM-D in-situ investigations indicated a major mass gain during the first minutes of immersion and only minor changes of the adsorbed mass after $30 \mathrm{~min}$, the substrates were in contact with the formulations for $20 \mathrm{~s}, 20-30 \mathrm{~min}$ and $24 \mathrm{~h}$, followed by a short rinsing with water and air-drying. Among the investigations performed, water contact angle measurements were expected to probe a fully hydrated adsorbate; XPS investigations were performed in a vacuum at ambient temperature and were expected to address dried adsorbates; and SFM measurements, done in air, possibly assessed partly hydrated adsorbates.

\subsubsection{Wettability of bio-functionalized substrates}

Fig. 2 shows photographs of the freshly cleaved HOPG and modified substrate for $20 \mathrm{~s}$ after the application of water droplets. As a consequence of contact for $20 \mathrm{~s}$, the contact angle changes from $79 \pm 1.5^{\circ}$ to $46 \pm 4^{\circ}$, indicating a modification of the surface to a more hydrophilic domain. Upon longer exposure of the HOPG substrate, from $30 \mathrm{~min}$ to $24 \mathrm{~h}$, contact angle values between $57 \pm 2.5^{\circ}$ to $54 \pm 1.5^{\circ}$ were obtained. The contact angle decreases in comparison to the freshly cleaved HOPG surface and underwent changes during progressive contact with the suspension for periods between $20 \mathrm{~s}$ and $24 \mathrm{~h}$.

As the wetting behavior of adsorbate-covered HOPG substrates was observed to be significantly influenced by the immersion time, it was concluded that the surface composition was modified and that these modifications at least partly persisted during the contact angle measurements. Considering the findings of the QCM-D investigations, the modification corresponded to a significant increase in the sample mass and, thus, the contact with the biopolymer formulation was expected to effectuate more clearly than the introduction of functional surface groups to the HOPG substrate. Surface analytical investigations were intended to reveal the composition of the layer system modifying the HOPG surface.

\subsubsection{Composition of the bio-functionalized surface}

The chemical composition of sample surfaces was studied using XPS. As the information depth of XPS is approximately $0.01 \mu \mathrm{m}$, investigations of thin adsorbates on HOPG facilitate the assessment of the composition of the adsorbates which, according to QCM-D measurements, were thinner than $10 \mathrm{~nm}$. However, estimating the thickness of the adsorbate based on XPS results required a structural model for an assumption the adsorbate layer. For reference and for comparison, freshly cleaved HOPG surfaces, a powder containing laccase and maltodextrin, purified laccase and, finally, maltodextrin powder were investigated. Table 1 presents the results of elemental surface concentrations obtained after contacting freshly cleaved HOPG with laccase mixture suspensions for various periods of time. Moreover, in Table 1 the labelling of the various freshly prepared laccase mixture suspensions is indicated.

Generally speaking, the XPS investigations detected carbon, oxygen, nitrogen, sodium and sulfur species as well as trace amounts below 0.1 at.\% of copper species. The increase in oxygen and, especially, nitrogen surface concentrations governed the changes of the surface elemental composition following immersion in the liquid formulation, as shown in Table 1 . The highest values of these surface concentrations were obtained for immersion times between $30 \mathrm{~min}$ and $24 \mathrm{~h}$. These values were attributed to have reached a saturation state of the surface.

Fig. 3A shows the plot of the mass adsorption curve measured by QCM-D. In Fig. 3B the normalized oxygen and nitrogen surface concentrations obtained from XPS investigations are displayed, varying the time of the carbons substrates in contact with the biopolymer formulation. In both cases, i.e. under continuous flux during the QCM-D measurement or when modifying the surface in static contact with the liquid formulation before XPS investigations, after $30 \mathrm{~min}$ a saturation of the surface was achieved. Therefore, the composition of this deposited material was evaluated in more detail by calculating and plotting the $[\mathrm{N}] /[\mathrm{O}]$ surface concentration ratio from the XPS results, as can be seen in Fig. 3B. After $20 \mathrm{~s}$ of immersion time there was a higher ratio of $[\mathrm{N}] /[\mathrm{O}]$ in comparison with the values obtained between $20 \mathrm{~min}$ and $24 \mathrm{~h}$. Considering the investigations of laccase-containing powders, the $[\mathrm{N}] /[\mathrm{O}]$ ratio after $20 \mathrm{~s}$ was similar to that observed for purified laccase, and the ratio after extended time in contact with the liquid formulation was similar to that observed for the mixture of laccase and maltodextrin. In Table 1, the elemental compositions are shown for a powder mixture containing laccase and maltodextrin, for pure maltodextrin, and for a purified laccase. Based on these findings, detecting a lower $[\mathrm{N}] /[\mathrm{O}]$ ratio in the adsorbate than in purified laccase may be related to the adsorbed species comprising not only laccase but also maltodextrin. This hypothesis will be explored in more detail below, based on the deconvolution of C1s XPS signals.

The adsorbate richest in nitrogen-containing species was obtained after $20 \mathrm{~s}$ of contact between HOPG and the biopolymer formulation, strongly increasing the wettability as compared to the pristine HOPG surface. Similarly, the change in the wetting behavior observed when comparing samples in contact with the laccase mixture suspension for $20 \mathrm{~s}, 20 \mathrm{~min}$ or $24 \mathrm{~h}$, on the other hand, seems to be accompanied by a decrease in the $[\mathrm{N}] /[\mathrm{O}]$ ratio. 
Table 1

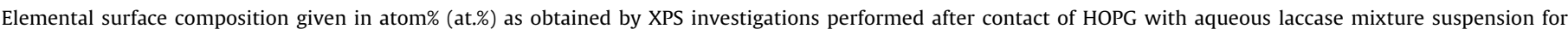

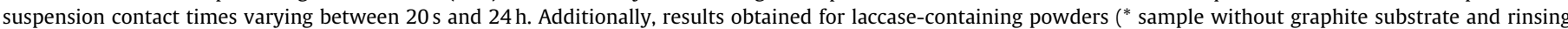
samples with water) and maltodextrin powder are shown. Finally, contributions to the C1s signal measured by XPS and obtained after deconvolution are listed.

\begin{tabular}{|c|c|c|c|c|c|c|c|c|c|c|c|c|c|c|}
\hline \multirow[t]{2}{*}{ Contact time } & \multirow[t]{2}{*}{ [0] } & & \multirow[t]{2}{*}[\mathrm{N}]{} & \multirow[t]{2}{*}[\mathrm{N}]{$/[\mathrm{O}]$} & \multirow[t]{2}{*}[\mathrm{S}]{} & \multirow[t]{2}{*}[\mathrm{Na}]{} & \multirow[t]{2}{*}[C]{} & \multirow{2}{*}{$\begin{array}{l}\text { Normalized C1s HOPG } \\
\text { signal (a.u) }\end{array}$} & \multirow{2}{*}{$\begin{array}{l}\text { Fraction of C1s signal } \\
\text { attributed to HOPG, (\%) }\end{array}$} & \multicolumn{5}{|c|}{ C1s signals not attributed to HOPG substrate } \\
\hline & & & & & & & & & & $285 \mathrm{eV}$ & $286.1 \mathrm{eV}$ & $286.7 \mathrm{eV}$ & $288.2 \mathrm{eV}$ & $289 \mathrm{eV}$ \\
\hline $0 \mathrm{~s}$ & & 1.1 & - & - & $<0.1$ & - & 98.8 & 1.0 & 100 & - & - & - & - & - \\
\hline $20 s$ & & 1.2 & 0.6 & 0.51 & $<0.1$ & $<0.1$ & 98.1 & $0.9 \pm 0.05$ & 93.6 & 2.8 & 1.1 & 1.2 & 0.9 & 0.4 \\
\hline $20 \mathrm{~min}$ & & 7.96 & 1.9 & 0.24 & $<0.1$ & 0.12 & 89.0 & $0.67 \pm 0.05$ & 77.7 & 6.1 & 4.5 & 6.8 & 3.2 & 1.8 \\
\hline $30 \mathrm{~min}$ & & 8.4 & 2.3 & 0.27 & $<0.1$ & 0.3 & 89 & $0.61 \pm 0.05$ & 74.7 & 6.3 & 5.3 & 8.1 & 3.5 & 2.1 \\
\hline $24 \mathrm{~h}$ & & 8.2 & 2.9 & 0.20 & $<0.1$ & 2.1 & 87.7 & $0.58 \pm 0.05$ & 70.7 & 10.9 & 5.3 & 7.7 & 3.4 & 2.0 \\
\hline Purified laccase & & 22.4 & 11.3 & 0.51 & 0.3 & 0.2 & 65.4 & $-^{*}$ & $-^{*}$ & 40 & 18 & 23 & 12 & 6 \\
\hline Laccase mixture & & 27.3 & 5.4 & 0.2 & 0.3 & 0.4 & 66.5 & -* & -* & 36 & 23 & 19 & 20 & 2.4 \\
\hline Maltodextrin & & 35.9 & $<0.1$ & - & - & - & 63.6 & - & - & 15.5 & 66.1 & 16.9 & 1.3 & - \\
\hline
\end{tabular}

Table 1 displays the percentage contributions obtained after deconvolution of the $\mathrm{C} 1 \mathrm{~s}$ signal area. It also shows the results of the $\mathrm{C} 1 \mathrm{~s}$ percentage contributions of the purified laccase by curvefitting into five components. Based on the primary structure of laccase from Trametes versicolor [39] and the elemental composition ( $c f$. Table 1 ), aliphatic carbon species $\mathrm{C}^{*}-\mathrm{C}$ and $\mathrm{C}^{*}-\mathrm{H}(\mathrm{C} 1 \mathrm{~s}$ binding energy (B.E.) of $285.0 \mathrm{eV}$ ), $\mathrm{C}^{*}-\mathrm{N}$ (B.E. $\left.286.1 \mathrm{eV}\right), \mathrm{C}^{*}-\mathrm{OH}$ and $C^{*}$-O-C (B.E. $286.7 \mathrm{eV}$ ), amide/peptide C*O-N (B.E. $288.2 \mathrm{eV}$ ), carbon atoms in carboxylic groups (B.E. $289.0 \mathrm{eV}$ ), and carbon from the polypeptide side chains contributed to the C1s signal [40]. The laccase-maltodextrin mixture contributions differ from that of the purified laccase due to a higher concentration of oxygen and $\mathrm{C}^{*}-\mathrm{O}$ bonds characteristic of polysaccharides such as maltodextrin and a lower concentration of nitrogen, $\mathrm{C}^{*}-\mathrm{N}$ and $\mathrm{C}^{*} \mathrm{O}-\mathrm{N}$ bonds [41] [42]. Moreover, taking into consideration that maltodextrincontaining carbohydrate is rich in oxygen but does not contribute to the nitrogen content, the $[\mathrm{N}] /[\mathrm{O}]$ concentration ratio and the $\left\{\left[\mathrm{C}^{*}-\mathrm{N}\right]+\left[\mathrm{C}^{*} \mathrm{O}-\mathrm{N}\right]\right\} /\left[\mathrm{C}^{*} \mathrm{O}\right]$ ratio were expected to be indicative of the molecular composition of the adsorbate on carbon.

Moreover, Table 1 includes the values obtained for freshly cleaved HOPG, and for HOPG in contact with the laccase mixture suspension for $20 \mathrm{~s}, 20 \mathrm{~min}, 30 \mathrm{~min}$ and $24 \mathrm{~h}$. Concerning the HOPG-based samples, the obtained C1s percentage contributions of the HOPG substrate were dominated by an asymmetric peak centered at $284.4 \mathrm{eV}$. This signal is considered a characteristic for graphitic carbon species, and signal features at $6.9 \mathrm{eV}$ higher binding energy values are ascribed to an energy loss of these electrons due to exciting $\pi-\pi^{*}$ transitions $[43,44]$. The low concentration of functional groups is indicated by the carbon concentration amounting to approximately 99 at.\%, as shown in Table 1 . As presented in Fig. S1D of the supplementary material, an analytical description for the silhouette of the graphitic C1s signal was developed, and this silhouette will be used when evaluating the $\mathrm{C} 1 \mathrm{~s}$ signal of biopolymer adsorbates on HOPG substrates. Fig. S1E, F and G show C1s XPS spectra of the adsorbates comprising laccase and maltodextrin after $20 \mathrm{~s}, 30 \mathrm{~min}$ or $24 \mathrm{~h}$ in contact with the biopolymer formulations. Considering the elemental compositions and the $\mathrm{C} 1 \mathrm{~s}$ percentage contributions of the biopolymer/HOPG samples and the mixed biopolymer powder, respectively, similar signals and, thus functional groups, contribute, on the one hand, to the adsorbates obtained after more than 20 min of contact time and, on the other hand, to the mixture of laccase and maltodextrin.

Fig. S2 displays the XPS signals in the N1s region obtained for the laccase mixture powder, purified laccase powder and the biofilm formed after $30 \mathrm{~min}$ of immersion on HOPG. The observed signals show an N1s binding energy of $400.1 \pm 0.1 \mathrm{eV}$ and are essentially centrosymmetric [45], thus representing the signal shape found for all the samples investigated. Binding energies of around $400 \mathrm{eV}$ were reported by Lucci et al. [46] as the nitrogen related to the amide bonds of the peptide backbone. Accordingly to the Cu2p3/2 peak signal approximately 0.04 at.\% of $\mathrm{Cu}$ species were detected for the laccase mixture powder, and a binding energy of around $933 \pm 0.5 \mathrm{eV}$ was obtained [47]. The S2p3/2 signal shows two peaks centered at $163.8 \mathrm{eV}$ for $\mathrm{S}^{*}-\mathrm{H}$ or $\mathrm{S}^{*}-\mathrm{S}$ [48] and $167.9 \mathrm{eV}$ to sulfur oxidized species due to the methionine and cysteine residues.

As indicated in Table 1 by the decrease in the normalized graphitic C1s signal intensity, an attenuation of the signal from the HOPG substrate was observed for samples which had been in contact with the laccase mixture suspension. Based on a layer model assuming a homogeneously distributed adsorbate layer with a uniform thickness. An attenuation of the C1s substrate signal by $40 \%$ was observed; for contact times between $20 \mathrm{~min}$ and $24 \mathrm{~h}$. This indicates that the effective layer thickness in the saturation state of the adsorption corresponds to half of the inelastic mean free path of C1s electrons in the adsorbate [49]. Assuming the same inelastic mean free path (IMFP) as for self-assembled monolayers alkylthiols on gold, i.e. $3 \mathrm{~nm}$ [50], a dry layer thickness of $1.5 \mathrm{~nm}$ for a smooth adsorbate layer is calculated from the investigations in a vacuum. However, assuming a rough adsorbate with a corrugation in a similar magnitude as the IMFP would yield a considerably higher amount of adsorbed material.

The composition of a film composed of a mixture of laccase and maltodextrin was estimated on the basis of surface sensitive XPS investigations. As substrate signals were detected with these measurements, the calculation was based on the assumption that the XPS results were representative of the film composition. Concerning the geometrical film structure, a homogeneous mixture of the constituents was assumed. The constituents considered were laccase and maltodextrin. The nitrogen concentration $[\mathrm{N}]$ in the maltodextrin powder was found to be lower than 0.1 at.\%. Therefore, all the nitrogen species detected by XPS were attributed to laccase, and, based on the above mentioned stoichiometry of laccase, the oxygen and carbon concentrations [O] in laccase were applied to obtain the film fraction occupied by laccase and, complementarily, by maltodextrin. The film composition was approximately $66.4 \mathrm{wt} \%$ laccase and $34.6 \mathrm{wt} \%$ maltodextrin.

Therefore, the surface topography resulting from the contact of freshly cleaved HOPG substrates with the laccase mixture suspension was investigated by SFM. The same samples as investigated by XPS were characterized. Moreover, phase contrast images governed by an adsorbate stiffness differing from that of the HOPG substrate were recorded under environmental conditions in tapping mode. The phase images thus allowed the determination of the changes to the surface properties related to viscoelasticity and compositional variation, based on the distinct damping of the oscillating tip in different regions on the surface. In soft deformable sample regions, as may be expected for an organic adsorbate like a protein layer, it may be assumed that a higher loading force leads to a larger contact area between the tip and the sample [51]. 

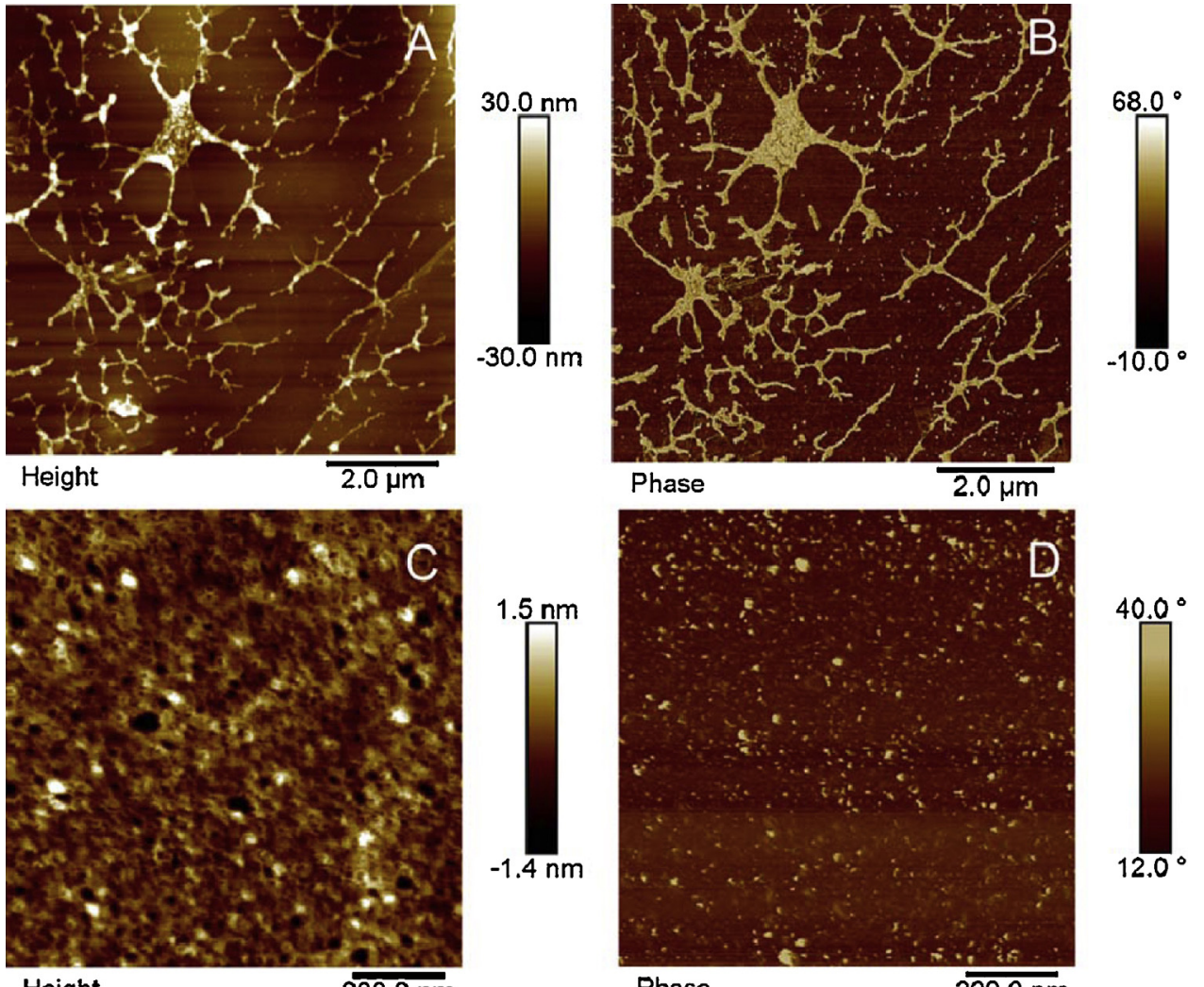

Height

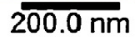

$$
\text { Phase }
$$

$2 \overline{200.0 \mathrm{~nm}}$
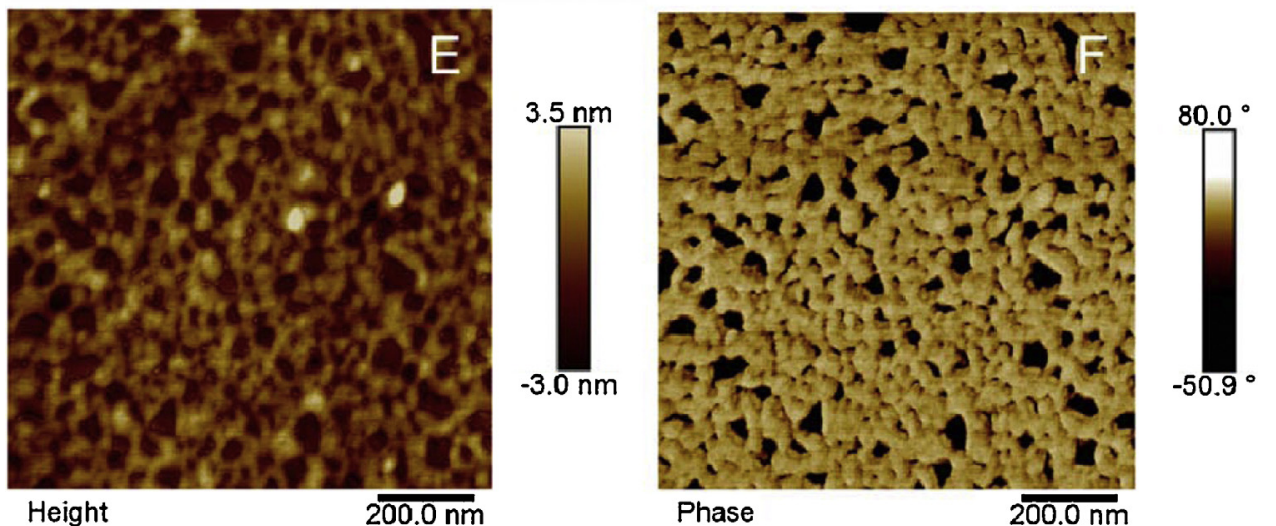

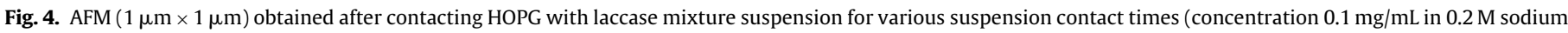

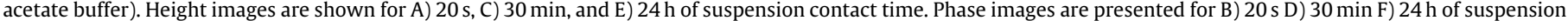
contact time.

The adsorbate-covered HOPG substrates after modification with the laccase mixture suspension were investigated for different contact time lengths between $20 \mathrm{~s}$ and $24 \mathrm{~h}$. Concerning the shorter contact time, Fig. 4A and B shows elevated structures in the height image which cover less than $10 \%$ of the sample surface area, and they are related to regions showing a high phase shift. The narrower elevated structures exhibited heights of around $18-26 \mathrm{~nm}$, and the height of wider structures was found to be $60-97 \mathrm{~nm}$.

Considering the height of the adsorbate, the values detected were much higher than the diameter of globular laccase monomers. Moreover, the arrangement of the adsorbate deposits appeared as a disrupted net with wide and high deposits situated around branching points. The appearance of the adsorbate surface was interpreted to result from a dewetting of the aqueous film upon drying, with the organic ingredients of the film being oriented along borderlines of receding water spots. Similar dewetting- driven adsorbate patterns were reported to result from the rupture of films on smooth substrates, e.g. for polystyrene films on the silicon wafers Sharma [52,53], or for thiol-passivated Au nanoparticles dissolved in organic solvents and deposited on silicon substrates [54]. In general, the dewetting of a liquid organic film is a selforganized process that forms microscale and nanoscale features $[55,56]$, induced by dispersion forces, leading to the rupture of the initially homogeneous film, typically by nucleation of holes on the film defects or in spots with high residual stress. Evaluating the pattern observed on the sample that was in contact with the suspension for short contact times such as $20 \mathrm{~s}$, it may be considered that the interplay between short- and long-range interfacial forces and, especially, the wettability of the substrate, govern whether films break up via spinodal dewetting or via (heterogeneous or thermal) nucleation [57]. As XPS investigations showed only minor concentrations of around 1.2 at.\% of oxygen and 0.6 at.\% 

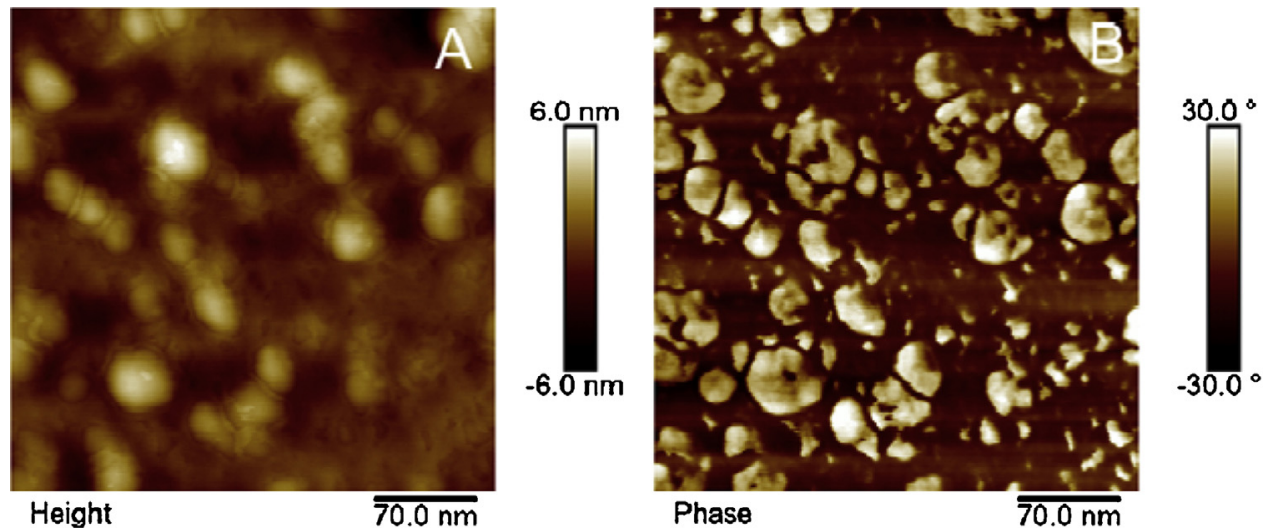

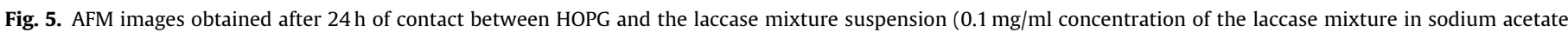
buffer), showing A) height $330 \mathrm{~nm} \times 330 \mathrm{~nm}, \mathrm{~B}$ ) phase, same position.

nitrogen containing species, the smooth regions were attributed to the surface of the HOPG substrate which is free from laccase and polysaccharides. Apparently, the rupture of the drying aqueous film was favored compared to the transport of the adsorptive towards the substrate surface or the formation of an adsorbate layer following nucleation and growth. This is generally attributed to the weak interactions between the carbon surface and the aqueous film and short contact times that do not favor irreversible adsorption [4]. Nonetheless, according to the results of the reported contact angle measurements the organic material inside the elevated structures that is insoluble in water appears to effectuate a significantly increased wettability of the sample surface.

A closer insight into the surface topography at a smaller scale is presented in AFM height images encompassing a width of $1 \mu \mathrm{m}$ after $30 \mathrm{~min}$ and $24 \mathrm{~h}$, as displayed in Fig. 5A and B. No high agglomerates or branched structures were found on the surface, and the phase images showed that a homogeneous layer had formed (data not shown). Thus, we conclude that the occurrence of the dewetting observed pattern may be characteristic for the poorly wettable pristine HOPG surface, and that this is not representative of the surfaces with adsorbed biopolymer layers.

After a contact time of $30 \mathrm{~min}$, a layer with a high package covers the surface and height differences of 2.3-4 nm were found between the bottom level of the holes and the predominant terminal level of the adsorbate, as can be seen in Fig. 4C and, similarly, in Fig. 4E. The HOPG surface consists of an atomically flat hexagonal arrangement of atoms in the basal plane (0001), and the terraces are limited by steps, i.e. defects resulting the cleavage process. No step-terrace defects could be distinguished due to the homogeneous coverage of the surface after $30 \mathrm{~min}$. A similar adsorbate structure was previously reported for bovine fibrogen adsorbed on HOPG, and Ta et al. attributed the formation of such a pattern to strong protein-protein interaction [58] as compared to the proteinsubstrate interaction as for Lo et al. in hydrophobins adsorbed in HOPG [59]. Moreover, Fig. 5A and B shows the height and phase image of the substrate in contact for $24 \mathrm{~h}$ at a smaller scale and at the same surface position. Spherical regions with distinct material properties compared to the underlying adsorbate layer and with an additional height of 3.2-4.3 nm were imaged all over the surface. Hard tapping was applied for imaging and the contrast in the phase image reveals that there is a difference in hardness between the particulate elevations and the regions around them. There are particles embedded in these regions which seem to be homogeneously smooth. They were interpreted to be laccase particles which give a contrast in the height and in the phase image with respect to the surrounding, and in places also the embedding, biopolymer layer.
In summary, height differences in the range of up to $8 \mathrm{~nm}$ were obtained from AFM investigations of the biopolymer layer systems for contact times between $20 \mathrm{~min}$ and $24 \mathrm{~h}$. The values corresponding to particle dots with a height of $5 \mathrm{~nm}$ agreed with the other data relating to single laccase molecules immobilized on HOPG without linkers [4]. Gonzáles et al. also observed a complex branched network with greater height values [4] of around 3-5 nm [23].

It is proposed a model of layer formation where the laccase monomers are surrounded by the maltodextrin that fills the voids between the protein particles, and thus a lateral interaction between laccase particles is not ruled out. Such a model structure can be associated with the experimental results shown, e.g., in Fig. 5A and B, which could be interpreted as two materials which have different degrees of stiffness and adhesive interaction with the tip, and, consequently, are imaged with a different phase contrast. The $[\mathrm{N}] /[\mathrm{O}]$ is similar to the laccase-maltodextrin mixture according to XPS, while the QCM-D based layer thickness calculation value is thinner than $10 \mathrm{~nm}$ and according to the AFM measurements, a layer with a roughness higher than $1 \mathrm{~nm}$ was imaged after $30 \mathrm{~min}$.

Finally, the effect of the water content in moist or even hydrated biopolymer layers on layer structure and thickness should be considered. Generally speaking, when discussing estimations of thickness of biomaterial adsorbate layers on smooth substrates in detail, there are several aspects of importance. Firstly, due to swelling effects [60] the water content of the adsorbate should be considered. The water uptake into proteins is considerable, and may amount to $30 \mathrm{wt} \%$, with the water uptake being related to the water binding capacity of the contributing amino acids. Moreover, the sorption isotherm may sharply increase at high water activities [61]. Thus, the thickness of a protein-based adsorbate layer will increase with increasing moisture and, consequently, the in-situ QCM-D investigations in aqueous environment may be expected to provide a higher layer thickness than the ex-situ measurements performed by AFM in air at 50\% r.h. or - even more the XPS studies performed in a vacuum. Secondly, the gravimetric and spectroscopic investigations enable an estimation of an effective layer thickness because the layer topography is not accessed. On the other hand, the microscopic investigations by AFM are local measurements considering the adsorbate roughness. Finally, AFM and XPS investigations were performed as rather static measurements, whereas during dynamic QCM-D investigations changes in the environment were shown to affect the mass of the adsorbate.

\section{Conclusions}

In this study changes in the surface composition and morphology of carbon based materials after contact with an aqueous 
biopolymer suspension containing maltodextrin and laccase from Trametes versicolor were investigated. Drying carbon substrates covered with liquid films obtained after suspension contact times lower than one minute gave rise to dewetting and laterally inhomogenous material deposition. Applying a contact time between 30 min and $24 \mathrm{~h}$ resulted in the hydrated adsorbate being approximately $4 \mathrm{~nm}$ thin and composed of hydrocarbonaceous species containing oxygen and nitrogen as heteroatoms and, especially, hydroxyl, carbonyl, amide and carboxyl groups. The findings indicate that in the saturation state the layer on carbon substrates consisted of adhering laccase and maltodextrin moieties and that a mixed polypeptide-carbohydrate layer was formed in a solid liquid interface. This is a promising and simple method for modifying to more hydrophilic domains the surface carbon based.

\section{Acknowledgements}

The authors cordially thank CONICIT Costa Rica for the funding, Prof. Dr. Bernd Mayer for the support and advice, Dr. Arno Cordes from “ASA Spezialenzyme GmbH”, Wolfenbüttel, Germany for providing laccase with a low amount of maltodextrin and Dr. Karsten Thiel for support in preparing the carbon-coated sensor samples and Robert H. Meißner for his support upon designing the graphical abstract.

\section{Appendix A. Supplementary data}

Supplementary data associated with this article can be found, in the online version, at http://dx.doi.org/10.1016/j.apsusc.2016.05. 097.

\section{References}

[1] Q. Wei, T. Becherer, S. Angioletti, J. Dzubiella, C. Wischke, A. Neffe, A. Lendlein, M. Ballauff, R. Haag, Angew. Chem. Int. Ed. 53 (2014) 8004-8031, http://dx doi.org/10.1002/anie.201400546.

[2] Q. Wei, T. Becherer, P.-L.M. Noeske, I. Grunwald, R. Haag, Adv. Mater. 26 (2014) 2688-2693, http://dx.doi.org/10.1002/adma.201304737.

[3] K. Rischka, K. Richter, A. Hartwig, M. Kozielec, K. Slenzka, R. Sader, I. Grunwald, Bio-inspired polyphenolic adhesives for medical and technical applications, in: J. von Byern, I. Grunwald (Eds.), Biological Adhesive Systems, Springer-Verlag, Wien, 2010, pp. 201-210

[4] K. González, A. González, M. Arévalo, L. Vázquez, A. Hernández, M. Falcón, Int J. Electrochem. Sci. 7 (2012) 1011-1026.

[5] E. Papirer, E. Brendle, F. Ozil, H. Balard, Carbon 37 (1999) 1265-1274, http:// dx.doi.org/10.1016/S0008-6223(98)00323-6.

[6] Y. Yan, O. Yehezkeli, I. Willner, Chem. Eur. J. 13 (2007) 10168-10175, http:// dx.doi.org/10.1002/chem.200700806.

[7] N. Misra, V. Kumar, N. Kumar, L. Varshney, Polymer 55 (2014) 6017-6024, http://dx.doi.org/10.1016/j.polymer.2014.09.035.

[8] M. Ardhaoui, M. Zheng, J. Pulpytel, D. Dowling, C. Jolivalt, F. Khonsari, Bioelectrochemistry 91 (2013) 52-61, http://dx.doi.org/10.1016/j.bioelechem. 2012.12.005.

[9] V. Hahn, A. Mikolasch, K. Manda, D. Gördes, K. Thurow, F. Schauer, J. Mol. Catal. B: Enzym. 60 (2009) 76-81, http://dx.doi.org/10.1016/j.molcatb.2009.04.002.

[10] N. Nady, K. Schroën, M. Franssen, R. Fokkink, M. Mohy, H. Zuihof, R. Boom, J. Colloid Interface Sci. 378 (2012) 191-200, http://dx.doi.org/10.1016/j.jcis. 2012.04.019.

[11] G. Fischer, S. Heumann, G. Guebitz, Modified Fibers with Medical and Specialty Applications, in: J. Edwards, G. Buschle, S. Goheen (Eds.), Springer, 2006, pp. 181-189, Chapter 11.

[12] A. Fillat, O. Gallardo, T. Vidal, F.I.J. Pastor, P. Díaz, M.B. Roncero, Carbohydr. Polym. 87 (2012) 146-152, http://dx.doi.org/10.1016/j.carbpol.2011.07.030.

[13] A. Dong, Y. Yu, J. Yuan, Q. Wang, X. Fan, Appl. Surf. Sci. 301 (2014) 418-427, http://dx.doi.org/10.1016/j.apsusc.2014.02.092.

[14] B. Hameed, A. Din, A. Ahmad, J. Hazard. Mater. 141 (2007) 819-825, http://dx doi.org/10.1016/j.jhazmat.2006.07.049.

[15] R. Chandra, L. Lehtonen, A. Ragauskas, Biotechnol. Prog. 20 (2004) 255-261, http://dx.doi.org/10.1021/bp0300366.

[16] F. Rodriguez, Carbon 36 (1998) 159-175, http://dx.doi.org/10.1016/S00086223(97)00173-5.

[17] X. Chu, K. Kinoshita, Mater. Sci. Eng. B 49 (1997) 53-60, http://dx.doi.org/10. 1016/S0921-5107(97)00100-1.

[18] S. Wang, Q. Zhang, R. Wang, S. Yoon, Biochem. Biophys. Res. Commun. 311 (2003) 572-576, http://dx.doi.org/10.1016/j.bbrc.2003.10.031.
[19] G. Dearnaley, J. Arps, Surf. Coat. Technol. 200 (2005) 2518-2524, http://dx.doi. org/10.1016/j.surfcoat.2005.07.077.

[20] P. Widsten, C. Heathcote, A. Kandelbauer, G. Guebitz, G. Nyanhongo, E. Nugroho, T. Kudanga, Process Biochem. 45 (2010) 1072-1081, http://dx.doi. org/10.1016/j.procbio.2010.03.022.

[21] H. Boehm, Carbon 40 (2002) 145-149, http://dx.doi.org/10.1016/S00086223(01)00165-8.

[22] H. Boehm, Carbon 32 (1994) 759-769, http://dx.doi.org/10.1016/00086223(94)90031-0.

[23] N. Chisholm, H. Mahfuz, V. Rangari, A. Ashfaq, S. Jeelani, Compos. Struct. 67 (2005) 115-124, http://dx.doi.org/10.1016/j.compstruct.2004.01.010.

[24] S. Witayakran, A. Ragauskas, Adv. Synth. Catal. 351 (2009) 1187-1209, http:// dx.doi.org/10.1002/adsc.200800775.

[25] M. Ferraroni, N. Myasoedova, V. Schmatchenko, A. Leontievsky, L. Golovleva, A. Scozzafava, F. Briganti, BMC Struct. Biol. 7 (2007) 60, http://dx.doi.org/10. 1186/1472-6807-7-60.

[26] A. Cañas, S. Camarero, Biotechnol. Adv. 28 (2010) 694-705, http://dx.doi.org/ 10.1016/j.biotechadv.2010.05.002.

[27] F. Xu, Ind. Biotechnol. 39 (2005) 38-50, http://dx.doi.org/10.1089/ind.2005.1. 38.

[28] S. Dean, B. Chang, T. Randolph, J. Carpenter, Arch. Biochem. Biophys. 365 (1999) 289-298, http://dx.doi.org/10.1006/abbi.1999.1175.

[29] S. Corveleyn, J. Remon, Pharm. Res. 13 (1996) 146-150, http://dx.doi.org/10. 1023/A:1016006106821.

[30] E. Dickinson, Food Hydrocoll. 25 (2011) 1966-1983, http://dx.doi.org/10. 1016/j.foodhyd.2010.12.001.

[31] G. Premagony, Adhesives and Coating Technology, in: A. Shukla (Ed.), Tata McGram- Hill Publishing Company Limited, New Delhi, 2008, pp. 43-86, Chapter 3.

[32] A. Majcherczyk, C. Johannes, A. Hüttermann, Enzyme Microb. Technol. 22 (1998) 335-341, http://dx.doi.org/10.1016/S0141-0229(97)00199-3.

[33] Y.R. Corrales, L. Wittig, M. Vieira, J. Faccioni, P.-N. Lisboa, K. Rischka, Appl. Adhes. Sci. 3 (2015) 7, http://dx.doi.org/10.1186/s40563-015-0032-6.

[34] D. Johannsmann, Phys. Chem. Chem. Phys. 10 (2008) 4516-4534, http://dx. doi.org/10.1039/b803960g.

[35] M. Hovgaard, M. Dong, D. Otzen, F. Besenbacher, Biophys. J. 6 (2007) 2162-2169, http://dx.doi.org/10.1529/biophysj.107.109686.

[36] F. Hook, J. Voros, M. Rodahl, R. Kurrat, P. Böni, J.J. Ramsden, M. Textor, N.D Spencer, P. Tengvall, J. Gold, B. Kasemo, Colloids Surf. B Biointerfaces 24 (2002) 155-170, http://dx.doi.org/10.1016/S0927-7765(01)00236-3.

[37] J. Rickert, A. Brecht, W. Göpel, Anal. Chem. 69 (1997) 1441-1448, http://dx. doi.org/10.1021/ac960875p.

[38] R. Fogel, J.L. Limson, Enzyme Microb. Technol. 49 (2011) 146-152, http://dx. doi.org/10.1016/j.enzmictec.2011.05.011.

[39] K. Piontek, M. Antorini, T. Choinowski, J. Biol. Chem. 40 (2002) 37663-37669, http://dx.doi.org/10.1074/jbc.M204571200.

[40] E. Vanea, V. Simon, Appl. Surf. Sci. 257 (2011) 2346-2352, http://dx.doi.org/ 10.1016/j.apsusc.2010.09.101.

[41] J. Stevens, S. Schroeder, Surf. Interface Anal. 41 (2009) 453-462, http://dx.doi. org/10.1002/sia.3047.

[42] P. Gerin, M. Genet, P. Rouxhet, Surf. Sci. Spectra 4 (1996) 28-32, http://dx.doi. org/10.1116/1.1247803.

[43] I. Retzko, W. Unger, Adv. Eng. Mater. 7 (2003) 519-522, http://dx.doi.org/10. 1002/adem.200320138.

[44] G. Speranza, N. Laidani, Diamond Relat. Mater. 13 (2004) 451-458, http://dx doi.org/10.1016/j.diamond.2003.11.075.

[45] S. Stamboroski, P. Stachera, Y.R. Corrales, G. Homann, W. Iraja, W. Kazuki, D. Salz, J. Ihde, Paul Noeske, Implementation of diverse non-centrosymmetric layer concepts for tuning the interface activity of a magnesium alloy, Appl. Adhes. Sci. 4 (2016), http://dx.doi.org/10.1186/s40563-016-0063-7.

[46] G. Lucci, C. Battocchio, M. Dettin, R. Gambaretto, G. Polzonettia, Surf. Interface Anal. 40 (2008) 210-214, http://dx.doi.org/10.1002/sia.2717.

[47] X. Quan, R. Uddin, A. Heiskanen, M. Parmvi, K. Nilson, M. Donolato, M. Hansen, G. Renac, A. Boisen, Chem. Commun. 51 (2015) 17313-17316, http://dx.doi. org/10.1039/C5CC04321B.

[48] D. Castner, Langmuir 12 (1996) 5083-5086, http://dx.doi.org/10.1021/ la960465w.

[49] Q. Wei, S. Krysiak, K. Achazi, T. Becherer, P.-L.M. Noeske, F. Paulus, H. Liebe, I. Grunwald, J. Dernedde, A. Hartwig, T. Hugel, R. Haag, Colloids Surf. B Biointerfaces 122 (2014) 684-692, http://dx.doi.org/10.1016/j.colsurfb.2014. 08.001.

[50] M.J. Esplandiu, P.-L.M. Noeske, Appl. Surf. Sci. 199 (2002), http://dx.doi.org/ 10.1016/S0169-4332(02)00608-6, 166-162.

[51] G. Pang, K.Z. Baba-Kishi, A. Patel, Ultramicroscopy 81 (2000) 35-40, http://dx. doi.org/10.1016/S0304-3991(99)00164-3.

[52] A. Sharma, G. Reiter, J. Colloid Interface Sci. 178 (1996) 383-399, http://dx doi.org/10.1006/jcis.1996.0133.

[53] R. Xie. A. Karim, J.F. Douglas, C. Han, R.A. Weiss, Phys. Rev. Lett. 81 (1998) 1251-1254, http://dx.doi.org/10.1103/PhysRevLett.81.1251.

[54] H. Alhummiany, S. Jarvis, R. Woolley, A. Stannard, M. Blunt, P. Moriarty, J. Mater. Chem. 21 (2011) 16983-16989, http://dx.doi.org/10.1039/ c1jm12182k.

[55] Y. Cai, B. Zhang, Langmuir 24 (2008) 5202-5208, http://dx.doi.org/10.1021/ la703923z.

[56] A. Higgins, R. Jones, Nature 404 (2000) 476-478, http://dx.doi.org/10.1038/ 35006597. 
[57] R. Seemann, S. Herminghaus, K. Jacobs, Phys. Rev. Lett. 86 (2001) 5535-5537, http://dx.doi.org/10.1103/PhysRevLett.86.5534.

[58] D. Kim, H. Blanch, C. Radke, Langmuir 18 (2002) 5841-5850, http://dx.doi.org/ 10.1021/la0256331.

[59] M. Klis, E. Maicka, A. Michota, J. Bukowska, S. Sek, J. Rogalski, R. Bilewicz,

Electrochim. Acta 52 (2007) 5591-5598, http://dx.doi.org/10.1016/j.electacta. 2007.02.008.
[60] P. Steinbach, B. Brooks, Proc. Natl. Acad. Sci. U. S. A. 90 (1993) 9135-9139, http://dx.doi.org/10.1073/pnas.90.19.9135.

[61] D. Chow, C. Morr, J. Am. Oil Chem. Soc. 56 (1976) A53-A62, http://dx.doi.org/ 10.1007/BF02671785. 